\title{
Experimental Infection of Culex (Culex) quinquefasciatus and Aedes (Stegomyia) aegypti with Wuchereria bancrofti
}

\author{
Cláudia ML Calheiros, Gilberto Fontes, Paul Williams*, Eliana MM Rocha/ ${ }^{+}$
}

\author{
Departamento de Patologia, Centro de Ciências Biológicas, Universidade Federal de Alagoas, Praça Afranio \\ Jorge s/non , 57010-020 Maceió, AL, Brasil *Departamento de Parasitologia, Instituto de Ciências Biológicas, \\ Universidade Federal de Minas Gerais, Belo Horizonte, MG, Brasil
}

\begin{abstract}
A study was conducted to determine the susceptibility of local strains of Culex quinquefasciatus and Aedes aegypti to infection with the strain of Wuchereria bancrofti that occurs in Maceio, State of Alagoas, Brazil. Cx. quinquefasciatus blood fed simultaneously on the same microfilariae carrier ingested more blood and 2-3x more microfilariae than Ae. aegypti. Survival rates of both species of insects living for 21 days after blood feeding on microfilaraemic patients were not significantly different from the survival rates of mosquitoes that blood fed on amicrofilaraemic individuals. W. bancrofti parasites underwent normal development in $\mathrm{Cx}$. quinquefasciatus, with third stage larvae first being recorded on the 11th day post infection, and their numbers increasing thereafter. Development of filariae in Ae. aegypti did not proceed beyond the first larval stage, and there was a progressively increasing number of non-viable larvae with the passage of time. It is concluded that Ae. aegypti is not involved in the transmission of $\mathrm{W}$. bancrofti in Maceió.
\end{abstract} Key words: Culex quinquefasciatus - Aedes aegypti - experimental infection - Wuchereria bancrofti - filariasis -
microfilariae

Culex quinquefasciatus is the principal vector of Bancroftian filariasis in areas where Wuchereria bancrofti has nocturnal periodicity, but, in other places, other species of mosquitoes may serve as insect hosts of the parasite (White 1989, WHO 1992). In Brazil, Causey et al. (1945), Rachou et al. (1955) and Rachou (1956) incriminated species of Aedes and Anopheles as hosts of secondary importance.

In Maceió, capital of the State of Alagoas, northeast Brazil, Deane et al. (1953) and Fontes et al. (1994) established that $C x$. quinquefasciatus is the most important insect host of W. bancrofti. However, Ae. aegypti is frequently found in human habitations in Maceió and it was considered necessary to determine if this species plays a role in the transmission of $W$. bancrofti in the city.

\section{MATERIALS AND METHODS}

Routine maintenance of mosquito colonies Adult females of $C x$. quinquefasciatus and Ae. aegypti were collected inside houses in urban areas of Maceió. After identification, each species was placed in a separate cage containing bowls of dechlo-

\footnotetext{
${ }^{+}$Corresponding author. Fax: +55-82-221.2501. E-mail: emmr@fapeal.br

Received 4 March 1998

Accepted 2 July 1998
}

rinated water for oviposition. The mosquitoes were maintained in an insectary at $27 \pm 2^{\circ} \mathrm{C}$ and of $80 \pm 10 \% \mathrm{RH}$, and provided a $10 \%$ glucose solution.

After eclosion, larvae were fed with ground food for laboratory mice. The cubes of mouse food had been previously sterilized by autoclaving. Pupae were transferred to water bowls and placed in clean insect cages for eclosion of adults. Emerged adult females of both species were provided a blood meal on pigeons weekly.

The established colony of $C x$. quinquefasciatus has been maintained since March 1993. For public health safety, related to the possible transmission of Yellow Fever and Dengue, the Ae. aegypti colony was maintained only for the duration of the study (January to August 1996).

Selection of volunteers - Four microfilariae carriers were randomly selected as hosts for mosquito blood meals. Each was informed of the nature of the study, and all gave written consent for their participation. The volunteers males, over 18 years of age, and not having been treated for filariasis, were microfilaraemic and with no clinical signs of lymphatic filariasis. Densities of microfilariae in the peripheral blood of the volunteers were determined by the method of Chularerk and Desowitz (1970). At the end of the study, the volunteers were treated with diethylcarbamazine in accordance with the therapeutic scheme recommended by the World Health Organization (WHO 1987). 
Experimental infection of mosquitoes - Nulliparous 2-5 day-old females of both species were used in the experiments. The sugar solution was removed $24 \mathrm{hr}$ before the blood meal to increase blood-feeding. Females of both species were exposed simultaneously to either the upper surface of the hand or on the forearm of the same volunteer between $23 \mathrm{hr}$ and midnight. The time of blood feeding coincided with the peak of microfilaraemia recorded in Maceió (Rocha et al. 1991). To reduce discomfort, blood feeding times were limited to 5-10 min for Ae. aegypti and to 10-20 min for $C x$. quinquefasciatus. Female mosquitoes that did not engorge were discarded.

Volume of ingested blood - The amount of ingested blood was determined by weighing 20 unfed females of each species immediately before blood feeding, and weighing 20 engorged females immediately after their blood meals. The volume of blood ingested was estimated by dividing the weight differences by $1,055(1,055 \mathrm{mg} / \mathrm{ml}$ being the approximate density of human blood).

Number of ingested microfilariae - The expected number of microfilariae ingested by the mosquitoes was calculated by multiplying the microfilariaemia of each volunteer by the mean volume of ingested blood. The actual numbers of ingested microfilariae were calculated by dissecting out the contents of the gut of a sample of the blood fed adults. The midgut was opened and a smear was made of the contained blood. The smear was fixed in methanol, stained with Giemsa, and the number of ingested microfilariae determined.

Development of $W$. bancrofti in Cx. quinquefasciatus and Ae. aegypti - Blood fed mosquitoes were maintained in the insectary for up to 21 days and provided with a $10 \%$ glucose solution as previously described (the usual time needed for complete development of $W$. bancrofti in an insect host is less than the period of observations in the present study).

After blood feeding, 2-5 females of both species of mosquitoes were removed daily, stunned by placing them in a freezer at $-10^{\circ} \mathrm{C}$ for $30 \mathrm{sec}$, and then dissected in a drop of buffered saline on a slide. After removal of the wings and legs, the head, thorax and abdomen were separated. Each of the body parts was transferred to separate drops of buffered saline and macerated to liberate filaria larvae. The numbers of larvae were recorded and their stage of development was noted.

Assessment of mosquito mortality - Mortality was recorded twice daily and dead mosquitoes dissected and examined for $W$. bancrofti larvae, as previously described. Survival rates were calculated by dividing the numbers of mosquitoes surviving for 21 days after the infective blood meal by the number of mosquitoes that took complete blood meals. Control mosquitoes of both species were allowed to blood feed on uninfected persons. The accumulative numbers of dead mosquitoes were plotted against time, and the correlation coefficients were calculated and compared.

\section{RESULTS}

Survival rates of mosquitoes - Observations on mortality and survival are summarized in Table I. Of the 1,084 Cx. quinquefasciatus mosquitoes which blood fed on $W$. bancrofti microfilaraemic volunteers, 476 survived for more than 21 days, a survival rate of 0.66 . For 926 female Ae. aegypti exposed to infection, the survival rate was 0.71 . Survival rates for mosquitoes that blood fed on individuals without microfilaraemia were 0.73 for Cx. quinquefasciatus and 0.79 for Ae. aegypti.

Among species, survival rates were not significantly different in mosquitoes exposed to infection $\left(c^{2}=3.21, p>0.05\right.$ for mosquitoes exposed to infection, and $c^{2}=0.49, p>0.05$ for mosquitoes that blood fed on individuals without microfilariae). Likewise, there was no significant differences in the survival of the same species after blood feeding on persons with or without microfilariae $(C x$. quinquefasciatus: $\mathrm{c}^{2}=2.17, \mathrm{p}>0.05 ;$ Ae. aegypti: $\mathrm{c}^{2}=2.49, \mathrm{p}>0.05$ ).

Fig. 1 shows the accumulative daily mortality of mosquitoes that blood fed on subjects with or without microfilariae. The four curves have the same correlation coefficient $(\mathrm{r}=0.99)$.

Volume of ingested blood - The mean volume of blood ingested was $3.37 \pm 0.63 \mathrm{ml}$ and $2.37 \pm 0.53$ $\mathrm{ml}$ for $C x$. quinquefasciatus and Ae. aegypti, respectively (Table II).

Number of ingested microfilariae - Sixty-one $C x$. quinquefasciatus were examined soon after they had taken an infective blood meal. Fifty-nine (97\%) harboured 3-102 microfilariae in the midgut (mean 19.8 \pm 19.5 microfilariae/female). Similarly, 76 female Ae. aegypti were examined after blood feeding. Sixty-four (84\%) were infected with 1-22 microfilariae (mean 5.7 \pm 5.6 microfilariae/female).

Females of both species of mosquito ingested more microfilariae than the density in the peripheral blood of the volunteers. The proportion of female $C x$. quinquefasciatus containing microfilariae was significantly higher than that recorded for female Ae. aegypti $\left(\mathrm{c}^{2}=4.5, \mathrm{p}<0.05\right)$. Also, the number of microfilariae ingested by female $C x$. quinquefasciatus was significantly higher than the number ingested by female Ae. aegypti $(\mathrm{p}<0.05)$.

The estimated microfilarial "concentration factor" varied from $2.6 \mathrm{x}$ to $7.6 \mathrm{x}$ for female $C x$. quinquefasciatus, and between $1.4 \mathrm{x}$ and $2.8 \mathrm{x}$ for 

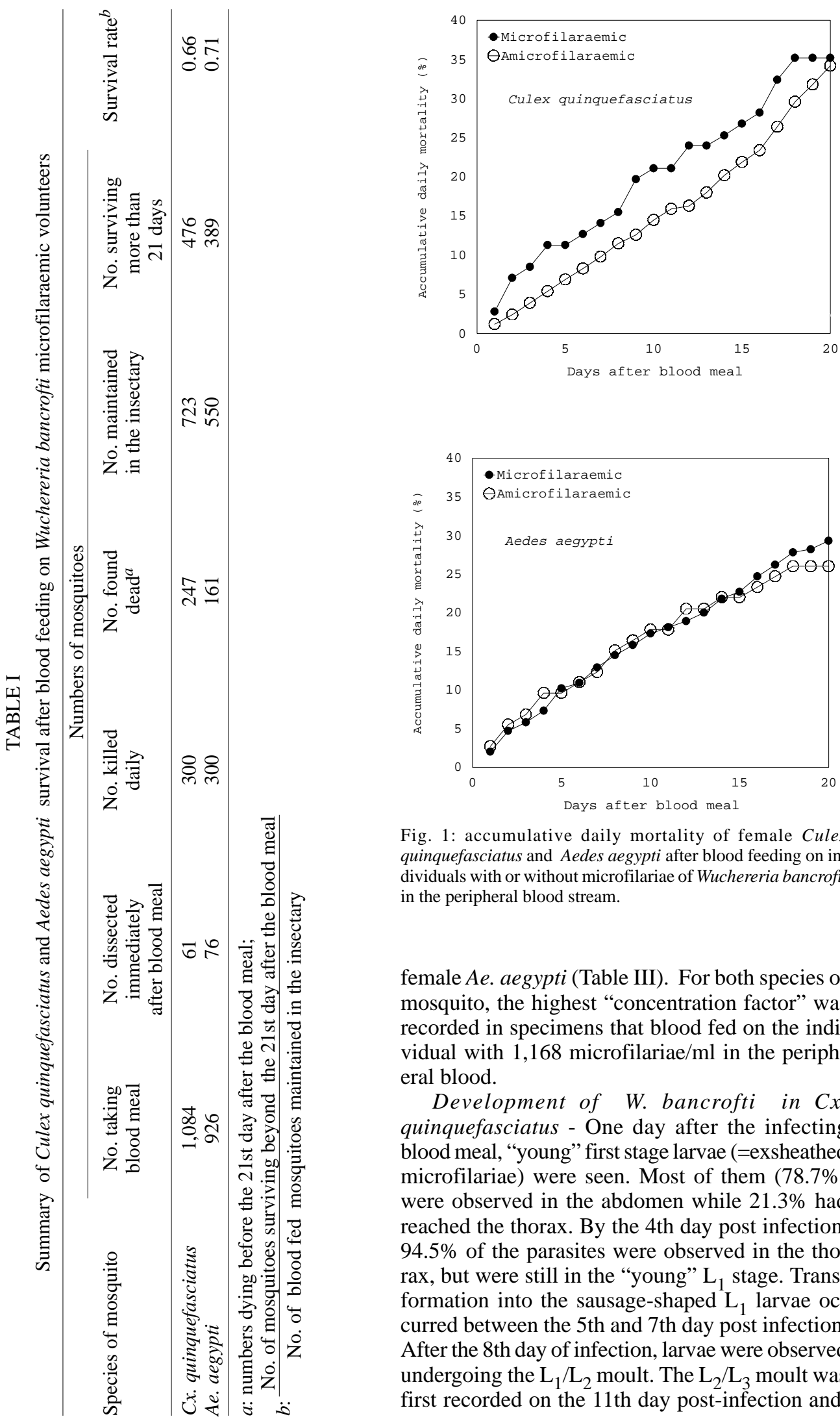

Fig. 1: accumulative daily mortality of female Culex quinquefasciatus and Aedes aegypti after blood feeding on individuals with or without microfilariae of Wuchereria bancrofti in the peripheral blood stream.

female Ae. aegypti (Table III). For both species of mosquito, the highest "concentration factor" was recorded in specimens that blood fed on the individual with 1,168 microfilariae/ml in the peripheral blood.

Development of $W$. bancrofti in $C x$. quinquefasciatus - One day after the infecting blood meal, "young" first stage larvae (=exsheathed microfilariae) were seen. Most of them $(78.7 \%)$ were observed in the abdomen while $21.3 \%$ had reached the thorax. By the 4th day post infection, $94.5 \%$ of the parasites were observed in the thorax, but were still in the "young" $\mathrm{L}_{1}$ stage. Transformation into the sausage-shaped $\mathrm{L}_{1}$ larvae occurred between the 5th and 7th day post infection. After the 8th day of infection, larvae were observed undergoing the $\mathrm{L}_{1} / \mathrm{L}_{2}$ moult. The $\mathrm{L}_{2} / \mathrm{L}_{3}$ moult was first recorded on the 11th day post-infection and, 
TABLE II

Estimated weight and volume of blood ingested by females Culex quinquefasciatus and Aedes aegypti

\begin{tabular}{|c|c|c|c|c|}
\hline Species of & Mean weight $\mathrm{c}$ & squitoes (mg) & Mean weight of blood & Mean volume of blood \\
\hline mosquito & Unfed & Engorged & ingested (mg) & ingested (ml) \\
\hline Cx. quinquefasciatus & $1.34 \pm 0.25^{a}$ & $5.09 \pm 0.52$ & $3.75 \pm 0.66$ & $3.57 \pm 0.63^{a}$ \\
\hline Ae. aegypti & $0.95 \pm 0.16^{a}$ & $3.45 \pm 0.53$ & $2.50 \pm 0.56$ & $2.37 \pm 0.53^{a}$ \\
\hline
\end{tabular}

$a$ : confidence limits $95 \%$; significant differences $(\mathrm{p}<0.05)$.

TABLE III

Differences between the expected and observed numbers of microfilariae ingested by females of Culex quinquefasciatus and Aedes aegypti

\begin{tabular}{|c|c|c|c|c|c|c|}
\hline \multirow{3}{*}{$\begin{array}{l}\text { Microfilaraemia } \\
\text { of volunteers } \\
(\mathrm{mf} / \mathrm{ml})\end{array}$} & \multicolumn{4}{|c|}{ Mean number of microfilariae/mosquito } & \multirow{2}{*}{\multicolumn{2}{|c|}{$\begin{array}{c}\text { Difference } \\
\text { (No. observed/No. expected) }\end{array}$}} \\
\hline & \multicolumn{2}{|c|}{ Observed } & \multicolumn{2}{|c|}{ Expected } & & \\
\hline & Culex & Aedes & Culex & Aedes & Culex & Aedes \\
\hline 906 & 8.8 & 3.5 & 3.4 & 2.0 & 2.6 & 1.8 \\
\hline 1,168 & 24.4 & 5.5 & 3.2 & 2.0 & 7.6 & 2.8 \\
\hline 1,215 & 13.8 & 6.8 & 4.3 & 3.4 & 3.2 & 2.0 \\
\hline 1,830 & 26.2 & 7.2 & 7.8 & 5.2 & 3.4 & 1.4 \\
\hline
\end{tabular}

thereafter, the numbers of $\mathrm{L}_{3}$ (infective larvae) increased. Twenty-one days after exposure to infection 216 out of 476 dissected Cx. quinquefasciatus mosquitoes yielded 860 infective larvae.

Development of W. bancrofti in Ae. aegypti During the first four days post-infection, the appearance of W. bancrofti in Ae. aegypti was similar to their appearance in $C x$. quinquefasciatus. After the 5th post-infection day, development of $W$. bancrofti showed little progress. A small number of exsheathed microfilariae developed into sausage shaped $\mathrm{L}_{1}$ larvae, but many of these had a shrunken, wrinkled appearance and were mostly immobile and were therefore considered dead. Development of the Maceió strain of W. bancrofti in the Maceió strain of Ae. aegypti is shown in Fig. 2 . None of the W. bancrofti larvae progressed beyond the $\mathrm{L}_{1}$ stage, dead larvae were recorded as early as 5-7 days post-infection, and, with a single exception, only dead larvae were recorded after the 13th post-infection day.

\section{DISCUSSION}

Because the recommendations of Asahina (1964) and Consoli and Lourenço-de-Oliveira (1994) were followed, it is reasonable to assume that the colonies of $C x$. quinquefasciatus and Ae. aegypti were adapted to laboratory conditions before the presently reported experiments were undertaken.
Neither species of mosquito showed adverse effects due to the presence of $W$. bancrofti. This contrasts with studies of Wharton (1960) and Crans (1973) in Malasya and East Africa, respectively. However, in these earlier studies, patients had much higher microfilaraemia than did the volunteers in Maceió. It is possible that migration of high numbers of developing filarial larvae within the mosquito body have an effect on vector survival.

Previous authors (Manson 1884, O'Connor \& Beatty 1936, Burton 1964, Crans 1973, McGreevy et al. 1982), working in different and widely separated parts of world, have recorded the disparity between the density of microfilariae in the peripheral blood of human hosts and the numbers of microfilariae ingested by arthropod hosts of the parasites. Various factors have been suggested to explain the apparent ability of mosquitoes to "concentrate" microfilariae (Hairston \& Jachowski 1968, Eberhard et al. 1988, Dickerson et al. 1989, Southgate \& Bryan 1992). The simplest explanation is the manner in which mosquitoes acquire blood meals. The classical paper of Gordon and Lumsden (1939), confirmed by Griffiths and Gordon (1952), shows that Ae. aegypti either obtains blood directly from a vessel or by lacerating vessels and, thus, forming a subcutaneous haemorrhage (pool feeding). Pool feeders take longer to engorge than do vessel feeders. When a mosquito pool feeds, there is more time for microfilariae to seep from the lacerated vessel into 


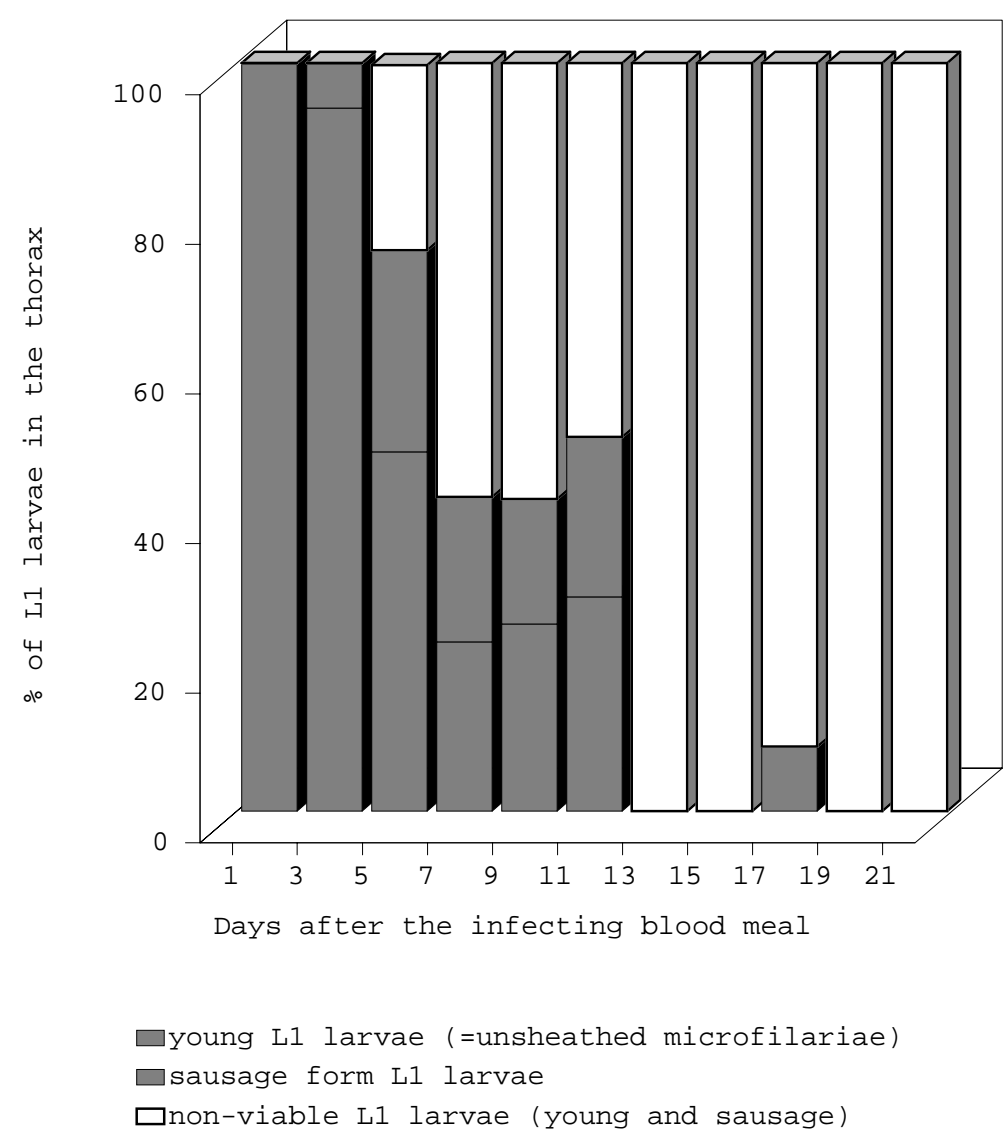

Fig. 2: developing stages of Wuchereria bancrofti found in the thorax of experimentally infected female Aedes aegypti.

the subcutaneous haemorrhage. However, it is recognized that further studies are necessary to understand the "concentration effect" of microfilariae in mosquitoes (Lowrie et al. 1989).

Complete development of $W$. bancrofti in $C x$. quinquefasciatus was expected because females of this species have been found naturally infected in Maceió (Fontes et al. 1994).

Experimental infection of Ae. aegypti with $W$. bancrofti has given variable results. In some cases (Ponnudurai et al. 1971, McGreevy et al. 1982), the parasites have developed to the $\mathrm{L}_{3}$ stage, whereas other researchers (Hunt \& Gunders 1990, Anosike \& Onwuliri 1992) obtained negative results. The present results are most similar to those of MacDonald and Ramachandran (1965) and Anosike and Onwuliri (1992), with larval development only progressing to the sausage-shaped phase.

The available literature provides evidence that susceptibility of Ae. aegypti to infection with filarial parasites is controlled by a sex-linked recessive gene (MacDonald \& Ramachandran 1965,
Ponnudurai et al. 1971, McGreevy et al. 1974). Although it has not yet been possible to make genetic studies on Ae. aegypti in Maceió, it is reasonable to suspect that the Maceió strain of Ae. aegypti is genetically incapable of supporting the development of $W$. bancrofti. For this reason, it is concluded that Ae. aegypti is not involved in the transmission of Bancroftian filariasis in Maceió.

\section{REFERENCES}

Anosike JC, Onwuliri CO 1992. Experimental Wuchereria bancrofti infection of Culex quinquefasciatus and Aedes aegypti. Angew Parasitol 33: 139-142.

Asahina S 1964. Food material and feeding procedures for mosquito larvae. Bull WHO 31: 465-466.

Burton GJ 1964. The intake of microfilariae of Wuchereria bancrofti by Culex pipiens fatigans in British Guiana. Ann Trop Med Parasitol 58: 333-338.

Causey OR, Deane MP, Costa O, Deane LM 1945. Studies on the incidence and transmission of filaria Wuchereria bancrofti, in Belém, Brazil. Am J Hyg 41: 143-149.

Chularerk P, Desowitz RS 1970. A simplified membrane filtration technique for the diagnosis of microfilare- 
mia. J Parasitol 56: 623-624.

Consoli RAGB, Lourenço-de-Oliveira R 1994. Principais Mosquitos de Importância Sanitária no Brasil, Editora Fiocruz, Rio de Janeiro, 228 pp.

Crans WJ 1973. Experimental infection of Anopheles gambiae and Culex pipiens fatigans with Wuchereria bancrofti in Coastal Africa. J Med Entomol 10: 189-193.

Deane LM, Rosa D, Rachou RG, Martins JS, Costa A, Gomes HM, Carvalho ME 1953. A filariose bancroftiana em Maceió, Alagoas: resultado de um inquérito realizado em 1952. Rev Bras Malariol D Trop 5: 17-22.

Dickerson JW, Eberhard ML, Lammie PJ, Roberts JM 1989. Further evidence of a skewed distribution of microfilariae in capillary blood. Trop Med Parasitol 40: 472-473.

Eberhard ML, Roberts JM, Lammie PJ, Lowrie Jr RC 1988. Comparative densities of Wuchereria bancrofti microfilariae in paired samples of capillary and venous blood. Trop Med Parasitol 39: 295-298.

Fontes G, Brito AC, Calheiros CML, Antunes CMF, Rocha EMM 1994. Situação atual da filariose bancroftiana na cidade de Maceió, Estado de Alagoas, Brasil. Cad Saúde Públ 10 (Supl. 2): 293-300.

Gordon RM, Lumsden WHR 1939. A study of the behaviour of the mouth-parts of mosquitoes when taking up blood from living tissue; together with some observations on the ingestion of microfilariae. Ann Trop Med Parasitol 33: 259-278.

Griffiths RB, Gordon RM 1952. An apparatus which enables the process of feeding by mosquitoes to be observed in the tissues of a living rodent, together with an account of the ejection of saliva and its significance in malaria. Ann Trop Med Parasitol 46: 311-319.

Hairston NG, Jachowski LA 1968. Analysis of the Wuchereria bancrofti population in the people of American Samoa. Bull WHO 38: 29-59.

Hunt RH, Gunders AE 1990. The susceptibility of five laboratory colonies of mosquitoes to the human nematode Wuchereria bancrofti (Cobbold). Ann Trop Med Parasitol 84: 381-386.

Lowrie RC, Eberhard ML, Lammie PJ, Raccurt CP, Katz SP, Duverseau YT 1989. Uptake and development of Wuchereria bancrofti in Culex quinquefasciatus that fed on Haitian carriers with different microfilaria densities. Am J Trop Med Hyg 41: 429-435.

MacDonald WW, Ramachandran CP 1965. The influence of gene $\mathrm{f}^{\mathrm{m}}$ of Aedes aegypti to seven strains of Brugia, Wuchereria and Dirofilaria. Ann Trop Med Parasitol 59: 64-73.

Manson P 1884. The metamorphosis of Filaria sanguinis hominis in the mosquito. Trans Linn Soc Lond 2: 366-390.
McGreevy PB, Theis JH, Lavoipierre MMJ, Clark J 1974. Studies on filariasis. III. Dirofilaria immitis: emergence of infective larvae from the mouthparts of Aedes aegypti. J Helminthol 48: 221-228.

McGreevy PB, Kolstrup N, Tao J, McGreevy MM, Marshal TF 1982. Ingestion and development of Wuchereria bancrofti in Culex quinquefasciatus, Anopheles gambiae and Aedes aegypti after feeding on humans with varying densities of microfilariae in Tanzania. Trans $R$ Soc Trop Med Hyg 76: 288296.

O'Connor FW, Beatty HA 1936. The early migrations of Wuchereria bancrofti in Culex fatigans. Trans $R$ Soc Trop Med Hyg 30: 125-127.

Ponnudurai T, Denham DA, Nelson GS 1971. The use of a membrane feeding technique for infecting mosquitoes with filarial worms transported between laboratories. J Helminthol 45: 415-418.

Rachou RG 1956. Transmissores da filariose bancroftiana no Brasil. Rev Bras Malariol D Trop 8: 267-268.

Rachou RG, Lima MM, Neto JAF, Martins CM 1955. Inquérito epidemiológico de filariose bancroftiana em uma localidade de Santa Catarina, como fase preliminar de uma prova profilática. Constatação de transmissão extradomiciliária por um novo vetor, Aedes scapularis. Rev Bras Malariol D Trop 7: 5170.

Rocha EMM, Fontes G, Vergetti G, Santos ACB, Fireman FAT, Dreyer G 1991. Periodicidade de microfilárias de Wuchereria bancrofti em filarióticos autóctones de Maceió-Alagoas. Rev Inst Med Trop S Paulo 33 (Supl. 8): 35.

Southgate BA, Bryan JH 1992. Factors affecting transmission of Wuchereria bancrofti by anopheline mosquitoes. 4. Facilitation, limitation and proportionality and their epidemiological significance. Trans $R$ Soc Trop Med Hyg 86: 523-530.

Wharton RH 1960. Studies on filariasis in Malaya: field and laboratory investigations of the vectors of a rural strain of Wuchereria bancrofti. Ann Trop Med Parasitol 54: 78-91.

White GB 1989. Lymphatic filariasis, p. 23-34. In Geografical Distribution of Arthropod-borne Diseases and their Principal Vectors, World Health Organization, Vector Biology and Control Division, WHO/VBC/89.967.

WHO - World Health Organization 1987. Control of Lymphatic Filariasis: A Manual for Health Personnel, WHO, Geneva, 89 pp.

WHO - World Health Organization 1992. Lymphatic Filariasis: the Disease and its Control, Fifth report of the WHO Expert committee on filariasis (WHO Technical Reports Series, n. 821), WHO Geneva, $75 \mathrm{pp}$. 